\title{
CDNF protects the nigrostriatal dopamine system and promotes recovery after MPTP treatment in mice
}

\author{
Mikko Airavaara ${ }^{1}$, Brandon K Harvey ${ }^{1}$, Merja H. Voutilainen ${ }^{3}$, Hui Shen ${ }^{1}$, Jenny Chou ${ }^{1}$, \\ Päivi Lindholm ${ }^{2}$, Maria Lindahl ${ }^{2}$, Raimo K. Tuominen ${ }^{3}$, Mart Saarma ${ }^{2}$, Yun Wang ${ }^{1}$, and \\ Barry Hoffer ${ }^{1}$
}

${ }^{1}$ Intramural Research Program, National Institute on Drug Abuse, $\mathrm{NIH}$, Baltimore, MD ${ }^{2}$ Institute of Biotechnology, University of Helsinki, Finland ${ }^{3}$ Faculty of Pharmacy, Department of Pharmacology and Toxicology, University of Helsinki, Finland

\begin{abstract}
Cerebral dopamine neurotrophic factor $(\mathrm{CDNF})$ is a recently discovered protein, which belongs to the evolutionarily conserved CDNF/MANF family of neurotrophic factors. CDNF has been shown to promote the survival of midbrain dopamine neurons in vivo. The degeneration of dopamine neurons following 1-methyl-4-phenyl-1,2,3,6-tetrahydropyridine (MPTP) -treatment is well characterized and efficacy in this model is considered a standard criterion for development of parkinsonian therapies. MPTP is a neurotoxin, which produces parkinsonian symptoms in humans, and in C57/B16 mice. To date, there are no reports about the effects of CDNF on dopamine neuron survival or function in the MPTP rodent model, a critical gap. Therefore, we studied whether CDNF has neuroprotective and neurorestorative properties for the nigrostriatal dopamine system after MPTP injections in C57/B16 mice. We found that bilateral striatal CDNF injections, given 20-h before MPTP, improved horizontal and vertical motor behavior. CDNF pre-treatment increased tyrosine hydroxylase (TH)-immunoreactivity in the striatum and in the substantia nigra pars reticulata (SNpr), as well as the number of TH-positive cells in substantia nigra pars compacta (SNpc). Post-treatment with CDNF, given 1 week after MPTP injections, increased horizontal and vertical behavior of mice, as well as dopamine fiber densities in the striatum and the number of TH-positive cells in SNpc. CDNF did not alter any of the analyzed dopaminergic biomarkers or locomotor behavior in MPTP-untreated animals. We conclude that striatal CDNF administration is both neuroprotective and neurorestorative for the TH-positive cells in the nigrostriatal dopamine system in the MPTP model, which supports the development of CDNFbased treatment for Parkinson's disease.
\end{abstract}

\section{Keywords}

CDNF; MANF; MPTP; Parkinson's disease

\section{Introduction}

Parkinson's disease (PD) is a progressive neurodegenerative disease. Although, many different neurons degenerate at various levels of the neuraxis, the major symptoms which lead patients to seek treatment are caused by a loss of nigrostriatal dopamine neurons. At the moment, there is no clinical treatment either to slow down and prevent the progression of

Corresponding author: Barry Hoffer, Intramural research program, National Institute on Drug Abuse, 251 Bayview blvd, Baltimore, MD 21224, Telephone: 443386 9096, bhoffer@intra.nida.nih.gov. 
the disease or to promote functional recovery by regenerating neurons and neuronal connections.

Rodent models of PD have been well characterized. Loss of dopaminergic circuitry can be induced in C57/B16 mice by 1-methyl-4-phenyl-1,2,3,6-tetrahydropyridine (MPTP) through intraperitoneal (i.p.) injections $(14,35)$. During the past decades, several neurotrophic factors have been studied in models of PD based on their postulated neuroprotective and neurorestorative properties $(5,25)$. The most studied and promising neurotrophic factor in animal models of PD thus far is glial cell line-derived neurotrophic factor (GDNF), which has been shown to be both neuroprotective and neuroregenerative against 6hydroxydopamine (6-OHDA) in rats (16) and MPTP in mice (37). However, intraputamenal GDNF treatment in human PD patients was not effective in a double-blind clinical trial (22), although two open label clinical studies, with small numbers of patients, showed clinical improvement $(13,34)$. Thus, other proteins with trophic activity on dopamine neurons need to be studied. Cerebral dopamine neurotrophic factor (CDNF; (27) and its homolog mesencephalic astrocyte-derived neurotrophic factor MANF (32) are secreted proteins which form a new evolutionary conserved protein family. MANF is protective on embryonic midbrain dopamine neurons in vitro (32). Both CDNF and MANF are neuroprotective against intra-striatal 6-OHDA toxicity in rats and also promote functional recovery $(27,38,39)$. However, the effects of CDNF or MANF in the MPTP mouse model of PD, one of the preclinical standards, have not been examined.

The aim of this study was to investigate whether bilateral CDNF injections into striatum are protective against MPTP and whether CDNF can promote functional recovery in adult mice after MPTP treatment. In mice, MPTP treatment causes greater toxicity on dopaminergic nerve terminals in the striatum compared to the cell bodies in the SNpc (35). Therefore, we administered CDNF bilaterally into the striata. We found that bilateral striatal CDNF injections of $10 \mu \mathrm{g}$, given before MPTP injections, improved motor behavior and that when CDNF $(10 \mu \mathrm{g})$ was injected 1 week after MPTP there was also improved locomotor behavior. The effects of CDNF to produce behavioral improvement before or after MPTP were associated with increased striatal tyrosine hydroxylase (TH) -immunoreactivity and substantia nigra dopamine (DA) cell numbers.

\section{Materials and methods}

\section{Subjects and MPTP injections}

Adult male C57/B16 mice (Charles River Laboratories, 10-12 weeks, 23-25g) were used in the MPTP experiments. Experimental procedures followed the guidelines of the "Principles of Laboratory Care" (National Institutes of Health publication No. 86-23, 1996) and were approved by the NIDA Animal Care and Use Committee. MPTP (Sigma) was injected four times at 2 hour intervals using $15 \mathrm{mg} / \mathrm{kg}$ and $20 \mathrm{mg} / \mathrm{kg}$ i.p for pre-treatment and posttreatment, respectively. The mouse strain, age and weight were chosen to produce significant dopamine depletion and a clear behavioral phenotype $(7,18,35)$. The lower dose of MPTP in the pretreatment experiment was used because of a significant loss of mice with higher dose, probably due to weaker physical condition after the survival surgery on the previous day.

\section{Surgical procedures}

Mice were anesthetized with chloral hydrate $(400 \mathrm{mg} / \mathrm{kg}$, i.p.) and placed in a stereotaxic apparatus. Mice were injected bilaterally into striatum (AP 0.5, ML 1.7, DV -3.5) with 10 $\mu \mathrm{g}$ CDNF or phosphate buffered saline (PBS) in a volume of $2 \mu \mathrm{l} /$ side. A Hamilton syringe was lowered into striatum and the injection speed was $0.5 \mu \mathrm{l} / \mathrm{min}$. The needle was left in 
place for two minutes after each injection. The dose, as well as production and purification of recombinant human CDNF protein were chosen as previously described (27). In both neuroprotection and neurorestoration experiments mice were divided into the two treatment groups based on balancing their 24-h locomotor behavior before CDNF and PBS injections.

\section{Behavioral measurements}

The locomotor behavior of the mice was measured using an infrared activity monitor (Accuscan, Columbus, OH). Each mouse was individually placed in a $42 X 42 X 31 \mathrm{~cm}$ plexiglass chamber for a 24 hour period, as previously described (9). The apparatus contains sixteen horizontal and eight vertical infrared sensors place $2.5 \mathrm{~cm}$ apart. Food and water were freely available throughout the experiment. Motor activity was calculated using the number of beams broken by the mice.

\section{TH immunostaining}

After the behavioral experiments, mice were anesthetized and perfused with saline followed by $4 \%$ paraformaldehyde (PFA) in phosphate buffer (PB). TH immunostaining was done on free-floating brain sections from striatum and substantia nigra using the $\mathrm{ABC}$ method as previously described (9). Briefly, sections were rinsed in $0.1 \mathrm{M}$ phosphate buffer (PB), pH 7.4, blocked with $4 \%$ bovine serum albumin (BSA) and $0.3 \%$ Triton x-100 in $0.1 \mathrm{M} \mathrm{PB}$. Sections were then incubated in rabbit TH antibody (Millipore, \#AB152, 1:500) overnight at $4{ }^{\circ} \mathrm{C}$. Sections were rinsed in $0.1 \mathrm{M} \mathrm{PB}$ and incubated in biotinylated horse anti-rabbit IgG (1:200; Vector Laboratories, Burlingame CA) for $1 \mathrm{~h}$, followed by incubation for $1 \mathrm{~h}$ with avidin-biotin-horseradish peroxidase complex. Staining was developed with 2, 3' diaminobenzidine tetrahydrochloride $(0.5 \mathrm{mg} / \mathrm{mL})$. Sections were then mounted on gelatin / chrome-alum coated slides and coverslipped.

To determine the optical density the sections were scanned with Nikon Super Coolscan 9000. TH fiber density from the dorsal striatum and SNpr was measured from three brain sections and quantitated relative to the control group. For cell counts histological images were acquired using an Infinity 3 camera, NIKON 80i microscope and QCapture Pro 5.0 software. TH positive cells were averaged from three sections (AP: $-3.16 \mathrm{~mm},-3.40 \mathrm{~mm}$, $-3.64 \mathrm{~mm}$ to bregma) as described previously (9). Image analysis was carried out with NIS elements software (Nikon). The quantitation of TH-positive cells was carried out using stereology and all measurements were done by personnel blinded as to treatment. TH pixel density was obtained by subtracting the background density.

\section{NeuN immunofluorescent staining}

Sections were rinsed three times with PB and incubated for $1 \mathrm{~h}$ with blocking solution (4\% BSA in $0.3 \%$ Triton X-100 in PB). Sections were incubated overnight with a mouse antiNeuN antibody (neuronal nuclei, 1:200, Chemicon) and rabbit anti-TH antibody and rinsed three times in PB. The primary antibody was visualized using the AlexaFluor 488 goat antimouse or AlexaFluor 568 goat anti-rabbit secondary antibody (Invitrogen). Brain sections were examined with a Nikon eclipse 80i microscope with a Q-imaging camera. Fluorescence intensity of NeuN-positive nuclei was quantified in the SNpc from three sections of each brain area and averaged using NIS Elements software. For Fig. 2 (below) images were adjusted equivalently for brightness and contrast for visualization.

\section{Western blotting}

Samples were sonicated for $10 \mathrm{~s}$ in $100 \mu$ l of RIPA lysis buffer with 1X protease inhibitor cocktail (Sigma-Aldrich, P8340) and centrifuged $10000 \mathrm{~g}$ for $5 \mathrm{~min}$. The supernatants were collected for TH western blots and protein concentrations were measured using the DC 
assay (Bio-Rad). The pellet was eluted with $50 \mu 1$ 1\% SDS and used for dopamine transporter (DAT) western blot and protein concentration measurement. Lysates were diluted with NuPAGE ${ }^{\circledR}$ LDS sample buffer and 2-mercaptoethanol and heated at $70^{\circ} \mathrm{C}$ for $10 \mathrm{~min}$. For TH analysis $20 \mu \mathrm{g}$, and for DAT analysis $10 \mu \mathrm{g}$, of protein were loaded into 4$12 \%$ Bris-Tris gel (NuPAGE ${ }^{\circledR}$, Invitrogen) and the electrophoresis was carried out in $1 \mathrm{X}$ MOPS buffer (Invitrogen). The proteins in the gel were transferred onto nitrocellulose membranes using NuPAGE transfer buffer (Invitrogen). The western blot procedures were carried out according to the Odyssey ${ }^{\circledR}$ protocol. Actin mouse antibody (1:1000 MAB1501, Millipore) was used as an endogenous control and TH was detected using a anti-TH rabbit antibody (1:1000, AB152, Millipore) and DAT was detected using rat anti-DAT antibody (1:1000, MAB369, Millipore). Infrared-labeled secondary antibodies of goat anti-mouse, rabbit and -rat were used for actin, TH and DAT, respectively. After immunostaining, the membranes were scanned by Li-Cor Odyssey Scanner and the bands were analyzed using ImageJ software.

\section{HPLC analysis}

The tissues obtained from each animal were homogenized in $0.1 \mathrm{M}$ perchloric acid and centrifuged at $13000 \mathrm{~g}$ for $15 \mathrm{~min}$. Dopamine (DA), 3,4-dihydroxyphenylacetic acid (DOPAC) and homovanillic acid (HVA) were measured by HPLC with electrochemical detection (21). The analytical column was a Symmetry C18 $3.5 \mu \mathrm{m}, 4.6 \times 150.0 \mathrm{~mm}$ (Waters, Milford, MA) and the mobile phase consisted of $0.01 \mathrm{M}$ sodium dihydrogen phosphate, 0.01 $\mathrm{M}$ citric acid, $2 \mathrm{mM}$ sodium EDTA, $1 \mathrm{mM}$ sodium octyl sulfate, $10 \%$ methanol and $\mathrm{pH}$ was 3.5. A flow rate of $0.9 \mathrm{ml} / \mathrm{min}$ was used and temperature was set to $25^{\circ} \mathrm{C}$. The system consisted of an ESA automated injection system, an ESA 582 pump, and a Coulochem III detector (ESA, Chelmsford, MA). An EZChrom EliteTM chromatography data analysis system (ESA Biosciences, Inc.) was used for data collection and analysis. Levels of DA, DOPAC and HVA were calculated as nmol/g of tissue weight.

\section{Effects of CDNF in MPTP-naïve animals}

Two additional experiments were carried out to analyze whether CDNF affects the dopaminergic system in MPTP-untreated naïve animals. In the first experiment mice were balanced into two groups based on their basal locomotor behavior and injected bilaterally into striatum either with PBS or CDNF $10 \mu \mathrm{g}$, and an additional eight normal mice were used as controls. After two weeks 24-h locomotor behavior was monitored and mice were decapitated, their brains removed and rapidly frozen in $-50^{\circ} \mathrm{C}$ isopentane and stored at $-80^{\circ} \mathrm{C}$. Bilateral tissue punches of the striatum and $\mathrm{SN}$ were taken from $1 \mathrm{~mm}$ coronal sections cut in a cryostat at $-20^{\circ} \mathrm{C}$. The other side was used for western blot experiments and the other side for HPLC analysis.

In another set of experiments thirty one Wistar rats (250-280 g) were injected with vehicle, GDNF $10 \mu \mathrm{g}$ or CDNF $10 \mu \mathrm{g}$ unilaterally into the striatum. These experiments were approved by the Committee for Animal Experiments of the University of Helsinki and the Chief veterinarian of the County Administrative Board. Two weeks later animals were given d-amphetamine ( $2.5 \mathrm{mg}$ s.c.) and, subsequently, motor behavior was measured for 2 hours. Afterwards animals were perfused, and TH immunostaining and cell counts in pars compacta and TH optical density in pars reticulata were carried out as described above.

\section{Statistical analysis}

Student's t-test and 1- and 2-way ANOVA were used for statistical analysis. In the 2-way ANOVA the within-subjects factor used was time and the between-subjects factor was CDNF-dose. Bonferroni test was used as post hoc analysis. Data are presented as mean \pm S.E.M. and $\mathrm{p}<0.05$ was considered statistically significant. 


\section{Results}

\section{CDNF protects TH-positive neurites and cell bodies against MPTP-induced toxicity}

Mice were balanced into treatment groups according to their 24-h behavior (Fig. 1A-B, blue columns). CDNF or PBS injections were given into striatum 20-h prior to MPTP (15 mg/kg, i.p. X4, every 2 hours). Locomotor behavior over 24 hours was measured two weeks later. CDNF-treated mice manifested a significantly greater distance travelled (Fig. 1A).

Statistical analysis showed significant effects of Time $F(1,13)=10.5$, $p<0.01$ and CDNF dose $\mathrm{F}(1,13)=5.1, \mathrm{p}<0.05$, but not Time $\mathrm{X}$ CDNF dose interaction $\mathrm{F}(1,13)=3.3$, 2-way ANOVA. The Bonferroni post hoc test showed a significant difference between PBS and CDNF injected mice on week $2(\mathrm{p}<0.05)$. To further analyze the temporal difference between these two groups, a 2-way ANOVA was carried out at two-hour intervals. The major difference between the groups was in the dark cycle, hours 12-24, when the mice were more active. Pretreatment with CDNF significantly increased total distance travelled (Fig. 1A, right panel, $\left.\mathrm{F}_{(1.13)}=7.3, \mathrm{p}<0.05\right)$. CDNF-treated mice also showed a significantly greater vertical activity (Fig. 1B). Statistical analysis showed a significant effect of CDNF dose $\mathrm{F}(1,13)=5.6$, $p<0.05$, but not Time $F(1,13)=2.8, p>0.05$ or Time $X$ CDNF dose interaction $F(1,13)=2.9$, $\mathrm{p}>0.05,2$-way ANOVA. Also, the Bonferroni post hoc test revealed a significant difference between PBS and CDNF treated mice $(\mathrm{p}<0.05)$. A 2-way ANOVA was carried out at twohour intervals showing that the major difference between the groups was during the dark cycle (Fig. 1B, right panel, $\left.\mathrm{F}_{(1.13)}=11.7, \mathrm{p}<0.01\right)$.

Immunohistochemical analysis showed that bilateral striatal CDNF injections protected $\mathrm{TH}-$ positive nerve fibers against MPTP treatment in the striatum (Fig. $1 \mathrm{C}, \mathrm{p}<0.01$, Student's ttest). In PBS-treated mice $27 \%$ of $\mathrm{TH}$ positive neurites were spared and in CDNF treated mice $62 \%$, as compared to MPTP-naïve normal mice. CDNF injections also protected neurites in the SNpr (Fig. 1D, p<0.05, t-test). In SNpr TH positive neurites were 61\% in PBS treated mice and $85 \%$ in CDNF treated mice as compared to MPTP-naïve normal mice. Intra-striatal CDNF-treatment also significantly rescued TH positive cells in the SNpc in the MPTP-treated mice (Fig. 1E, p $<0.05$, t-test). The numbers of TH-positive cells were $44 \%$ in PBS-treated mice and $85 \%$ in CDNF-treated mice as compared to non-lesioned naïve mice.

\section{Selectivity of CDNF-mediated neuroprotection in SNpc}

A question that arises from the results is whether the CDNF-induced neuroprotective effect is selective to dopamine neurons or is it secondary to the prevention of cell loses in SNpc. To study this, a set of brain sections from experiment one was double stained with NeuN (a marker for neurons, green) and TH (red, Fig. 2). Since NeuN-positive cells do not correlate well with TH-positive cells in SNpc $(6,12) \mathrm{NeuN}$ can be used as a marker for other neuronal populations in SNpc. No difference in NeuN fluorescence intensity in $\mathrm{SNpc}$ was found between PBS + MPTP treated mice and CDNF + MPTP treated mice $(\mathrm{p}=0.21$, Student's ttest) while significant increase in TH immunoreactivity was found in mice pretreated with CDNF. These data suggest that CDNF-mediated protection is selective for dopamine neurons in substantia nigra.

\section{CDNF does not alter behavior or TH-immunoreactivity in MPTP naïve animals}

Another question that arises from the results is that does CDNF increase TH in MPTP-naïve mice that might cause a neuroprotective effect simply by higher TH levels? Two experiments were carried out to analyze whether CDNF affects the dopaminergic system in MPTP-untreated naïve animals. Sixteen mice were balanced into two groups based on their basal locomotor behavior and injected bilaterally into striatum either with PBS or $10 \mu \mathrm{g}$ of $\mathrm{CDNF}$, and an additional eight normal mice were used as controls. Two weeks later locomotor behavior, striatal TH and DAT levels and dopamine, DOPAC and HVA 
concentrations were analyzed. No difference in horizontal or vertical 24-h locomotor activity was found between PBS and CDNF groups (data not shown). CDNF did not alter TH levels in the striatum (Fig. 3A\&D, p=0.25, 1-way ANOVA), in SN (Fig. 3B, p=0.40, 1way ANOVA), or DAT levels in the striatum (Fig. 3C\&E, p=0.64, 1-way ANOVA). There were no differences in dopamine, DOPAC and HVA concentrations in the striatum or SN between CDNF and PBS treated mice (Table 1, p>0.05, Student's t-test). However, DOPAC/DA ratio, indicator of dopamine metabolism, and (DOPAC+HVA)/DA ratio, indicator of dopamine turnover, were significantly higher in the striatum of CDNF treated mice ( $p<0.01$ and $p<0.05$, respectfully, Student's t-test).

Thirty one rats were injected with vehicle, GDNF $10 \mu \mathrm{g}$ or CDNF $10 \mu \mathrm{g}$ unilaterally into the striatum. Two weeks later animals were given d-amphetamine $(2.5 \mathrm{mg} / \mathrm{kg}$, s.c. $)$ and, subsequently, motor behavior was measured for 2 hours. Afterwards animals were perfused, and TH immunostaining and cell counts in pars compacta and TH optical density in pars reticulata were carried out as described above. Locomotor activity, induced by damphetamine, did not differ between vehicle, CDNF and GDNF treatment groups (vehicle: $100 \pm 14$; CDNF 113 \pm 24 ; GDNF: $123 \pm 26$, values are related to vehicle, $F_{(2.28)}=0.26, p=0.74$, 1-way ANOVA, Fig. 3F). The number of TH positive cells was similar in all treatment groups (vehicle: $89 \pm 5$; CDNF 95 \pm 8 ; GDNF: $98 \pm 8$, values are related to the number of $\mathrm{TH}$ positive cells in the non-treated hemisphere, $\mathrm{F}_{(2.26)}=0.43$, $\mathrm{p}=0.65$, 1-way ANOVA, Fig. 3G). In addition, TH optical density in the SNpr was similar in all treatment groups (vehicle: $100 \pm 10$; CDNF 91 \pm 7 ; GDNF: $109 \pm 8$, values are normalized to the TH optical density in the control group, $\mathrm{F}_{(2.25)}=0.93, \mathrm{p}=0.41$, 1-way ANOVA, Fig. $\left.3 \mathrm{H}\right)$.

\section{CDNF promotes recovery after MPTP-injections}

Twenty eight mice were injected with four doses of MPTP at 2-h intervals. Animals were equally separated into two groups according to their locomotor activity one week after MPTP injections and were treated with either CDNF or PBS into the striatum. Posttreatment with CDNF, compared to PBS, significantly improved total distance travelled (Fig. 4A, p<0.05, t-test) and vertical activity (Fig. 4B, p $<0.05$, t-test) over 24 hours at one week after injection. The analysis at $2 \mathrm{~h}$ intervals with two-way ANOVA further indicated that there was a significant difference in distance travelled (Fig. 4A. $\mathrm{F}_{(1.26)}=5.7$, $\mathrm{p}<0.05$ ) and vertical activity (Fig. 4B, $\mathrm{F}_{(1.26)}=7.1$, p $<0.05$ ) after $\mathrm{CDNF}$ treatment during the dark period. Bilateral striatal CDNF $10 \mu \mathrm{g}$ injections incremented TH positive nerve fiber immunoreactivity after MPTP-induced toxicity in the striatum (Fig. 4C, p<0.05, t-test). In striatum $\mathrm{TH}$ positive neurites were $15 \%$ in PBS treated mice and 31\% in CDNF treated mice as compared to MPTP-naïve mice. CDNF did not alter TH optical density in the $\mathrm{SNpr}$ (Fig. $4 \mathrm{D})$. However, CDNF treatment significantly increased the number of $\mathrm{TH}$ positive cells in the SNpc as compared to PBS treatment (Fig. 4E, p<0.05, t-test). In SNpc TH-positive cells were 51\% in PBS treated mice and 65\% in CDNF treated mice as relation to MPTP-naïve normal mice.

\section{Discussion}

The present results show that CDNF can protect against MPTP toxicity and restore motor function in mice when given before or after MPTP. Here we provide both histochemical and behavioral evidence indicating that CDNF exerts positive neurotrophic effects on adult dopamine neurons in the MPTP-lesioned mice. We found that CDNF $(10 \mu \mathrm{g})$ injections, given bilaterally into the striatum before MPTP injections, improved locomotor behavior and increased TH-immunoreactivity in the striatum and $\mathrm{SNpr}$, and also protected THpositive cells in the SNpc significantly. Furthermore, when administered one week after MPTP, CDNF improved locomotor behavior and increased TH-immunoreactivity in the striatum and the number of TH-positive cells in SNpc. These results suggest that CDNF 
treatment not only protects the cell bodies of midbrain dopamine neurons from degeneration but also restores dopaminergic circuitry.

We used MPTP in C57/B16 mice to elicit disruption of midbrain dopamine circuits. MPTP is a neurotoxin that affects nigrostriatal dopamine neurons in human, in non-human primates and in mice, and produces motor symptoms resembling PD (18). In humans and non-human primates MPTP irreversibly destroys the midbrain dopamine neurons. C57/B16 mice are susceptible to MPTP and dopamine terminals are destroyed transiently; there is some spontaneous regeneration from the surviving cells at many weeks-months after lesioning. Hence, it is important to examine toxicity within a 2-4 week window (10). There is still on going debate whether MPTP treatment in mice does cause death of dopamine neurons or loss of dopamine phenotype. In two studies it has been indicated that there is loss of dopamine cells in SNpc followed up to two or four weeks after MPTP administration, respectively $(3,17)$. However, in other studies where mice have been followed up to 5 and 6 months it has been reported that there is partial spontaneous recovery, and chemical and histological reductions within nigrostriatal dopaminergic circuitry are then approximately $70-80$ from normal $(31,33)$. Also, our finding that CDNF can promote recovery is in line with the latter studies and suggests that some of the MPTP-induced toxic effects can be reversed. If dopamine cells would be fully dead and totally gone, CDNF and any other neurotrophic factor would be ineffective. Also, it should be kept in mind that in advanced human PD patients many neuronal elements are still present albeit with a loss of the dopamine phenotype (24). Indeed the concept of neurorestoration therapy in PD is to restore the function of neurons that still have their neuronal architectural structure. Of course it can be possible that CDNF facilitates regeneration of dopamine neurons, but our experiment does not distinguish whether CDNF has this effect or does it restore the dopamine phenotype. To answer this question would require an extensive time course follow-up and pre-labeling of dopamine neurons.

The finding that CDNF-induced neuroprotection was stronger than the effects found in the neurorestorative experiments is also in line with previous findings with CDNF (27), MANF (39) and GDNF (37). It is likely that early treatment with these trophic factors may more effectively reduce DA fiber degeneration.

Although, GDNF has been shown to be a potent survival factor for embryonic dopaminergic neurons in vitro, there is some controversy about whether GDNF provides neuroprotection in addition to its well established neurorestoration properties in mouse MPTP models. Tomac and co-workers, using a similar experimental design as in this study, found that exogenous GDNF is protective against MPTP and promotes recovery (37). In a study by Cheng and co-workers MPTP ( $35 \mathrm{mg} / \mathrm{kg}$, s.c.) was injected once daily for seven days and GDNF was injected unilaterally into striatum either before, during or after MPTP treatment (8). Although this study failed to show a correlation between behavior and the extent of the lesion, GDNF pretreatment and posttreatment increased dopamine concentrations in the striatum. A study by Kojima and co-workers found that adenovirus mediated GDNF overexpression increased dopamine levels in striatum when the virus was given one week after MPTP ( 2 doses $40 \mathrm{mg} / \mathrm{kg}$, s.c. on consecutive days) exposure (19). In contrast, a study by Eberhardt and co-workers, where adenovirus-GDNF was injected into striatum and one week later MPTP (30 mg/kg, i.p.) was injected daily for five consecutive days, it was found that GDNF over-expression alone did not produce neuroprotection of dopamine neurons (11). Also, another study by the same group, where the same MPTP treatment protocol and a conditional RET-deficient mouse model was used, indicated that endogenous GDNF-RET signaling does not provide protection against MPTP-induced cell loss (20). Taken together these studies suggest that GDNF's most prominent effect in the MPTP-lesioned mouse midbrain is to facilitate regrowth of the dopaminergic axon terminals. Consistent with 
clinical findings (Lang et al, 2006) it is likely that GDNF's beneficial effect may be limited to selective conditions in PD. In this study, we report that CDNF protects the cell bodies of dopamine neurons when given before or after lesioning, revealing beneficial properties of this novel neurotrophic factor that may provide additional beneficial properties to PD patients.

Structural analysis of CDNF and MANF indicates that they are two-domain proteins (30). The CXXC disulphide bridge of the carboxy-terminal domain resembles the active site of oxidoreductases and isomerases, which may be involved in ER-stress function; the aminoterminal domain is homologous to saposins, which are proteins known to bind lipids (30). Recent studies indicate that the C-terminal part of MANF is crucial for protective effects against apoptotic cell death and it resembles SAP domain of Ku70 that can bind to and block the proapoptotic molecule Bax (15). MANF and CDNF are expressed in neurons and in nonneuronal tissue $(26,27)$ and the expression of MANF is increased by tunicamycin, ischemia and status epilepticus $(4,23,26,28,36)$. MANF protects cells from tunicamycin, an inhibitor of N-linked glycosylation and an agent known to produce ER-stress (4). MANF also protects neurons against cerebral ischemia in vivo $(1,2)$. The mechanisms underlying these functions may also be involved in the neuroprotective and restorative effects of CDNF against MPTP.

The role of CDNF in the normal development or maintenance of dopamine neurons is not well characterized. Vertebrates encode for both MANF and CDNF genes, whereas invertebrates contain only a single homolog (26). In Drosophila it has been shown that deletion of MANF results in degeneration of dopamine axons and significant decrease in dopamine concentration (29). In the adult mouse brain, both CDNF and MANF proteins are detected mostly in the neurons in the striatum, substantia nigra, cortex, hippocampus, cerebellum, and MANF has also been localized to some dopamine neurons $(26,27)$. These data suggest that CDNF is present endogenously in adult brain. In this study, we found that exogenously applied CDNF did not upregulate TH and DAT or alter dopamine concentrations in MPTP-naïve animals. We found that DOPAC/DA and (DOPAC+HVA)/ DA rations were increased after CDNF treatment suggesting that dopamine metabolism and turnover is increased. However, the effect of increased dopamine turnover was not associated with increased horizontal or vertical locomotor activity, and therefore the physiological role of CDNF in dopamine neurons in non-lesioned animals is not clear at present. Furthermore, our results in non-lesioned animals suggest that the neuroprotective effect observed is not due to simply increased TH or DAT levels.

In rats it has been indicated that NeuN-positive cells do not correlate well with TH-positive cells in SNpc (6) and a study with cynomolgus monkeys showed no correlation between histological markers of cellular death and NeuN in SNpc after MPTP administration (12). As we did not find any differences in the levels of NeuN positive cells in SNpc, our results suggest that the neuroprotective effect of CDNF is selective for dopamine neurons. However, this conclusion should be considered with caution since there is no published data about the effects of MPTP on the number of NeuN positive cells in SNpc in mice.

In conclusion, the present study is the first to report the positive neuroprotective and neurorestorative effects of intra-striatal CDNF administration in the nigrostriatal dopamine system against MPTP. Importantly CDNF had clear neuroprotective effect on dopamine cell bodies when MPTP was given after or before striatal CDNF injections. Furthermore, CDNF neither altered TH and DAT expression levels or dopamine and its metabolite concentrations in the nigrostriatal dopamine system in MPTP naïve animals. These results further support the development of CDNF-based treatment strategies to stop progression or to promote recovery in PD. 


\section{Acknowledgments}

Recognition of support: This research was supported by the IRP of NIDA, NIH, DHHS. We would like to thank Carl Lupica, Alex Hoffman and Christopher Richie for their help with the study.

\section{References}

1. Airavaara M, Chiocco MJ, Howard DB, Zuchowoski KL, Peränen J, Liu C, Fang S, Hoffer BJ, Wang Y, Harvey BJ. Widespread cortical expression of MANF by AAV serotype 7: localization and protection against ischemic brain injury. Exp Neurol. 2010 manuscript accepted for publication.

2. Airavaara M, Shen H, Kuo CC, Peränen J, Saarma M, Hoffer B, Wang Y. Mesencephalic astrocytederived neurotrophic factor reduces ischemic brain injury and promotes behavioral recovery in rats. J Comp Neurol. 2009; 515(1):116-124. [PubMed: 19399876]

3. Anderson DW, Neavin T, Smith JA, Schneider JS. Neuroprotective effects of pramipexole in young and aged MPTP-treated mice. Brain Res. 2001; 905(1-2):44-53. [PubMed: 11423078]

4. Apostolou A, Shen Y, Liang Y, Luo J, Fang S. Armet, a UPR-upregulated protein, inhibits cell proliferation and ER stress-induced cell death. Exp Cell Res. 2008; 314(13):2454-2467. [PubMed: 18561914]

5. Bespalov MM, Saarma M. GDNF family receptor complexes are emerging drug targets. Trends Pharmacol Sci. 2007; 28(2):68-74. [PubMed: 17218019]

6. Cannon JR, Greenamyre JT. NeuN is not a reliable marker of dopamine neurons in rat substantia nigra. Neurosci Lett. 2009; 464(1):14-17. [PubMed: 19682546]

7. Chen YH, Harvey BK, Hoffman AF, Wang Y, Chiang YH, Lupica CR. MPTP-induced deficits in striatal synaptic plasticity are prevented by glial cell line-derived neurotrophic factor expressed via an adeno-associated viral vector. FASEB J. 2008; 22(1):261-275. [PubMed: 17690153]

8. Cheng FC, Ni DR, Wu MC, Kuo JS, Chia LG. Glial cell line-derived neurotrophic factor protects against 1-methyl-4-phenyl-1,2,3,6-tetrahydropyridine (MPTP)-induced neurotoxicity in C57BL/6 mice. Neurosci Lett. 1998; 252(2):87-90. [PubMed: 9756328]

9. Chou J, Luo Y, Kuo CC, Powers K, Shen H, Harvey BK, Hoffer BJ, Wang Y. Bone morphogenetic protein-7 reduces toxicity induced by high doses of methamphetamine in rodents. Neuroscience. 2008; 151(1):92-103. [PubMed: 18082966]

10. Date I, Yoshimoto Y, Imaoka T, Miyoshi Y, Gohda Y, Furuta T, Asari S, Ohmoto T. Enhanced recovery of the nigrostriatal dopaminergic system in MPTP-treated mice following intrastriatal injection of basic fibroblast growth factor in relation to aging. Brain Res. 1993; 621(1):150-154. [PubMed: 8106113]

11. Eberhardt O, Coelln RV, Kugler S, Lindenau J, Rathke-Hartlieb S, Gerhardt E, Haid S, Isenmann $\mathrm{S}$, Gravel C, Srinivasan A, et al. Protection by synergistic effects of adenovirus-mediated Xchromosome-linked inhibitor of apoptosis and glial cell line-derived neurotrophic factor gene transfer in the 1-methyl-4-phenyl-1,2,3,6-tetrahydropyridine model of Parkinson's disease. J Neurosci. 2000; 20(24):9126-9134. [PubMed: 11124990]

12. Garrido-Gil P, Belzunegui S, San Sebastian W, Izal-Azcarate A, Lopez B, Marcilla I, Luquin MR. 1-Methyl-4-phenyl-1,2,3,6-tetrahydropyridine exposure fails to produce delayed degeneration of substantia nigra neurons in monkeys. J Neurosci Res. 2009; 87(2):586-597. [PubMed: 18798285]

13. Gill SS, Patel NK, Hotton GR, O’Sullivan K, McCarter R, Bunnage M, Brooks DJ, Svendsen CN, Heywood P. Direct brain infusion of glial cell line-derived neurotrophic factor in Parkinson disease. Nat Med. 2003; 9(5):589-595. [PubMed: 12669033]

14. Heikkilä RE, Hess A, Duvoisin RC. Dopaminergic neurotoxicity of 1-methyl-4-phenyl-1,2,5,6tetrahydropyridine in mice. Science. 1984; 224(4656):1451-1453. [PubMed: 6610213]

15. Hellman M, Arumae U, Yu LY, Lindholm P, Peranen J, Saarma M, Permi P. Mesencephalic astrocyte-derived neurotrophic factor (MANF) has a unique mechanism to rescue apoptotic neurons. J Biol Chem. 2011; 286(4):2675-2680. [PubMed: 21047780]

16. Hoffer BJ, Hoffman A, Bowenkamp K, Huettl P, Hudson J, Martin D, Lin LF, Gerhardt GA. Glial cell line-derived neurotrophic factor reverses toxin-induced injury to midbrain dopaminergic neurons in vivo. Neurosci Lett. 1994; 182(1):107-111. [PubMed: 7891873] 
17. Jackson-Lewis V, Jakowec M, Burke RE, Przedborski S. Time course and morphology of dopaminergic neuronal death caused by the neurotoxin 1-methyl-4-phenyl-1,2,3,6tetrahydropyridine. Neurodegeneration. 1995; 4(3):257-269. [PubMed: 8581558]

18. Jackson-Lewis V, Przedborski S. Protocol for the MPTP mouse model of Parkinson's disease. Nat Protoc. 2007; 2(1):141-151. [PubMed: 17401348]

19. Kojima H, Abiru Y, Sakajiri K, Watabe K, Ohishi N, Takamori M, Hatanaka H, Yagi K. Adenovirus-mediated transduction with human glial cell line-derived neurotrophic factor gene prevents 1-methyl-4-phenyl-1,2,3,6-tetrahydropyridine-induced dopamine depletion in striatum of mouse brain. Biochem Biophys Res Commun. 1997; 238(2):569-573. [PubMed: 9299553]

20. Kowsky S, Poppelmeyer C, Kramer ER, Falkenburger BH, Kruse A, Klein R, Schulz JB. RET signaling does not modulate MPTP toxicity but is required for regeneration of dopaminergic axon terminals. Proc Natl Acad Sci U S A. 2007; 104(50):20049-20054. [PubMed: 18056810]

21. Krasnova IN, Bychkov ER, Lioudyno VI, Zubareva OE, Dambinova SA. Intracerebroventricular administration of substance $\mathrm{P}$ increases dopamine content in the brain of 6-hydroxydopaminelesioned rats. Neuroscience. 2000; 95(1):113-117. [PubMed: 10619467]

22. Lang AE, Gill S, Patel NK, Lozano A, Nutt JG, Penn R, Brooks DJ, Hotton G, Moro E, Heywood $\mathrm{P}$, et al. Randomized controlled trial of intraputamenal glial cell line-derived neurotrophic factor infusion in Parkinson disease. Ann Neurol. 2006; 59(3):459-466. [PubMed: 16429411]

23. Lee AH, Iwakoshi NN, Glimcher LH. XBP-1 regulates a subset of endoplasmic reticulum resident chaperone genes in the unfolded protein response. Mol Cell Biol. 2003; 23(21):7448-7459. [PubMed: 14559994]

24. Leenders KL, Salmon EP, Tyrrell P, Perani D, Brooks DJ, Sager H, Jones T, Marsden CD, Frackowiak RS. The nigrostriatal dopaminergic system assessed in vivo by positron emission tomography in healthy volunteer subjects and patients with Parkinson's disease. Arch Neurol. 1990; 47(12):1290-1298. [PubMed: 2123623]

25. Lim ST, Airavaara M, Harvey BK. Viral vectors for neurotrophic factor delivery: a gene therapy approach for neurodegenerative diseases of the CNS. Pharmacol Res. 2010; 61(1):14-26. [PubMed: 19840853]

26. Lindholm P, Peränen J, Andressoo JO, Kalkkinen N, Kokaia Z, Lindvall O, Timmusk T, Saarma M. MANF is widely expressed in mammalian tissues and differently regulated after ischemic and epileptic insults in rodent brain. Mol Cell Neurosci. 2008; 39(3):356-371. [PubMed: 18718866]

27. Lindholm P, Voutilainen MH, Laurén J, Peränen J, Leppänen VM, Andressoo JO, Lindahl M, Janhunen S, Kalkkinen N, Timmusk T, et al. Novel neurotrophic factor CDNF protects and rescues midbrain dopamine neurons in vivo. Nature. 2007; 448(7149):73-77. [PubMed: 17611540]

28. Mizobuchi N, Hoseki J, Kubota H, Toyokuni S, Nozaki J, Naitoh M, Koizumi A, Nagata K. ARMET is a soluble ER protein induced by the unfolded protein response via ERSE-II element. Cell Struct Funct. 2007; 32(1):41-50. [PubMed: 17507765]

29. Palgi M, Lindström R, Peränen J, Piepponen TP, Saarma M, Heino TI. Evidence that DmMANF is an invertebrate neurotrophic factor supporting dopaminergic neurons. Proc Natl Acad Sci U S A. 2009; 106(7):2429-2434. [PubMed: 19164766]

30. Parkash V, Lindholm P, Peränen J, Kalkkinen N, Oksanen E, Saarma M, Leppanen VM, Goldman A. The structure of the conserved neurotrophic factors MANF and CDNF explains why they are bifunctional. Protein Eng Des Sel. 2009; 22(4):233-241. [PubMed: 19258449]

31. Petroske E, Meredith GE, Callen S, Totterdell S, Lau YS. Mouse model of Parkinsonism: a comparison between subacute MPTP and chronic MPTP/probenecid treatment. Neuroscience. 2001; 106(3):589-601. [PubMed: 11591459]

32. Petrova P, Raibekas A, Pevsner J, Vigo N, Anafi M, Moore MK, Peaire AE, Shridhar V, Smith DI, Kelly J, et al. MANF: a new mesencephalic, astrocyte-derived neurotrophic factor with selectivity for dopaminergic neurons. J Mol Neurosci. 2003; 20(2):173-188. [PubMed: 12794311]

33. Ricaurte GA, Langston JW, Delanney LE, Irwin I, Peroutka SJ, Forno LS. Fate of nigrostriatal neurons in young mature mice given 1-methyl-4-phenyl-1,2,3,6-tetrahydropyridine: a neurochemical and morphological reassessment. Brain Res. 1986; 376(1):117-124. [PubMed: 3487376] 
34. Slevin JT, Gerhardt GA, Smith CD, Gash DM, Kryscio R, Young B. Improvement of bilateral motor functions in patients with Parkinson disease through the unilateral intraputaminal infusion of glial cell line-derived neurotrophic factor. J Neurosurg. 2005; 102(2):216-222. [PubMed: 15739547]

35. Sundström E, Stromberg I, Tsutsumi T, Olson L, Jönsson G. Studies on the effect of 1-methyl-4phenyl-1,2,3,6-tetrahydropyridine (MPTP) on central catecholamine neurons in C57BL/6 mice. Comparison with three other strains of mice. Brain Res. 1987; 405(1):26-38. [PubMed: 2882814]

36. Tadimalla A, Belmont PJ, Thuerauf DJ, Glassy MS, Martindale JJ, Gude N, Sussman MA, Glembotski CC. Mesencephalic astrocyte-derived neurotrophic factor is an ischemia-inducible secreted endoplasmic reticulum stress response protein in the heart. Circ Res. 2008; 103(11):12491258. [PubMed: 18927462]

37. Tomac A, Lindqvist E, Lin LF, Ogren SO, Young D, Hoffer BJ, Olson L. Protection and repair of the nigrostriatal dopaminergic system by GDNF in vivo. Nature. 1995; 373(6512):335-339. [PubMed: 7830766]

38. Voutilainen MH, Back S, Peranen J, Lindholm P, Raasmaja A, Mannisto PT, Saarma M, Tuominen RK. Chronic infusion of CDNF prevents 6-OHDA-induced deficits in a rat model of Parkinson's disease. Exp Neurol. 2011; 228(1):99-108. [PubMed: 21185834]

39. Voutilainen MH, Bäck S, Pörsti E, Toppinen L, Lindgren L, Lindholm P, Peranen J, Saarma M, Tuominen RK. Mesencephalic astrocyte-derived neurotrophic factor is neurorestorative in rat model of Parkinson's disease. J Neurosci. 2009; 29(30):9651-9659. [PubMed: 19641128] 
A
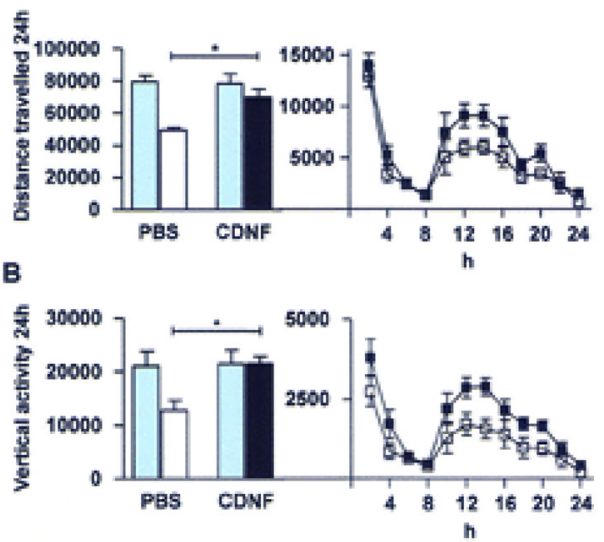

$\mathrm{c}$

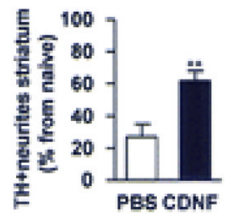

Naive

D

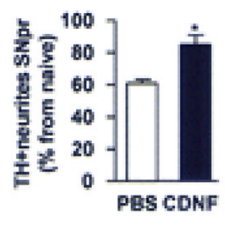

PBS

E
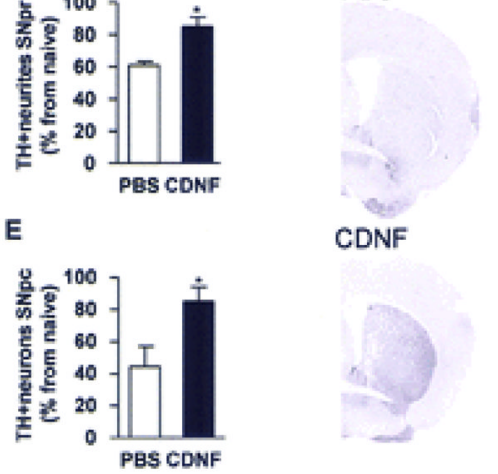

CDNF

Figure 1. Striatal cerebral dopamine neurotrophic factor (CDNF) injections protect midbrain dopamine circuitry against 1-methyl-4-phenyl-1,2,3,6-tetrahydropyridine (MPTP)

Mice were balanced into two groups according to their 24-h locomotor behavior (blue columns in A and B left panel). Bilateral CDNF $10 \mu \mathrm{g}$ or PBS injections were given into the striatum $20 \mathrm{~h}$ prior to four MPTP injections. White columns and square symbols are PBS + MPTP; black columns and square symbols are CDNF + MPTP. Locomotor behavior and tyrosine hydroxylase (TH) immunoreactivity were measured 2 weeks later. (A) Distance traveled (cm). (B) Vertical activity after MPTP treatment. (C-E) MPTP and PBS white columns and MPTP and CDNF black columns. (C) TH optical density in the striatum. (D) TH optical density in the substantia nigra pars reticulata (SNpr). (E) TH-positive cells in the substantia nigra pars compacta (SNpc). Representative photomicrographs from striatum from normal control (naive), PBS-, and CDNF-treated mice. (A-C) $n=6-9$; (D, E) $n=5-8$. *Significant difference $(p<0.05)$ between PBS- and CDNF-treated mice 2 weeks after MPTP treatment, in (A) and (B) with Bonferroni post hoc test and in $(\mathrm{C}-\mathrm{E})$ with Student's $t$ test. 

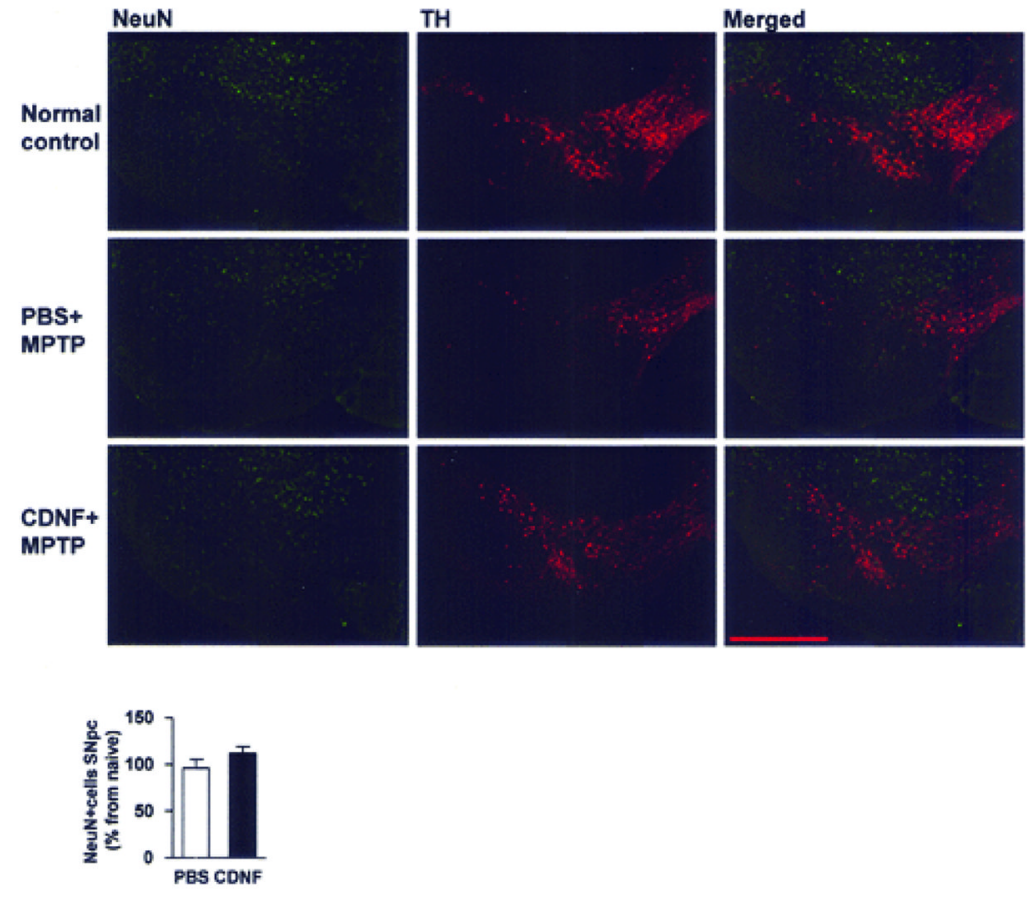

Figure 2. NeuN fluorescence intensity after MPTP treatment in CDNF and PBS injected mice Bilateral CDNF $10 \mu \mathrm{g}$ or PBS injections were given into the striatum $20 \mathrm{~h}$ prior to four MPTP injections. Mice were perfused and the brains were fixed with $4 \%$ paraformaldehyde (PFA) 2 weeks later and NeuN (neuronal nuclei) and tyrosine hydroxylase (TH) immunoreactivity were carried. Analysis of NeuN fluorescence intensity in SNpc showed no differences between PBS + MPTP-treated mice and CDNF + MPTP-treated mice. The data are shown in relation to nonlesioned naive mice. Scale bar: $0.5 \mathrm{~mm}$. In the bar graph $n=4$ per group. 

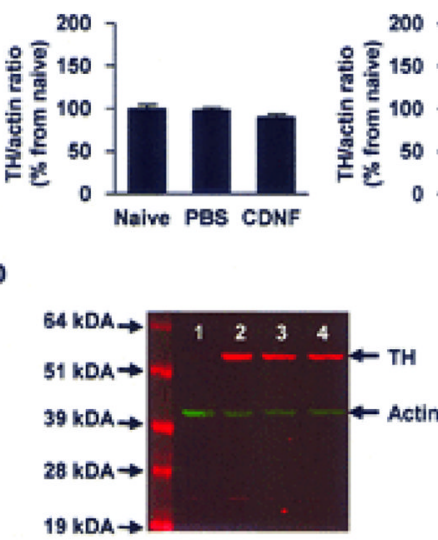

F

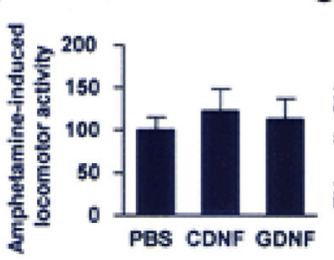

G

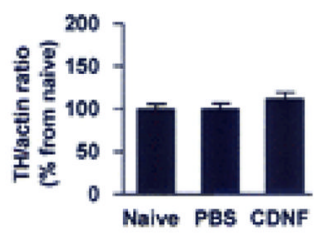

E
C

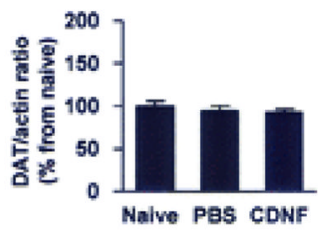

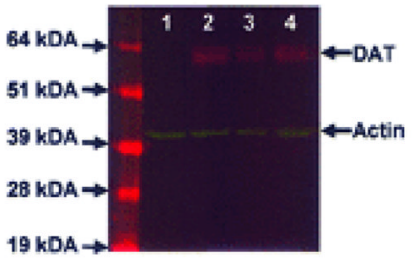

H
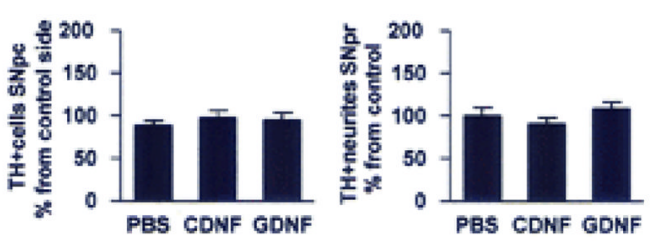

Figure 3. Effects of striatal CDNF injections in MPTP-naive animals

Mice were balanced according to their behavior and placed into two groups (A-E). MPTPnaive mice were injected bilaterally into striatum with either PBS or CDNF $10 \mu \mathrm{g}$. Two weeks later striata were collected and $\mathrm{TH}$ and dopamine transporter (DAT) levels were analyzed by Western blotting. (A, D) TH levels in the striatum in normal naive, PBS-, and CDNF-treated mice. (D) Lane 1: Cerebral cortex negative control, lane 2: naive, lane 3: PBS, lane 4: CDNF. TH (58.5 kDa) shown in red and actin (42 kDa) in green. (B) TH levels in substantia nigra $(\mathrm{SN})$. (C, E) DAT levels in striatum. (E) Lane 1: Cerebral cortex negative control, lane 2: naive, lane 3: PBS, lane 4: CDNF. DAT (68.5 kDa) shown in red and actin in green. Rats were given unilateral intrastriatal injections of vehicle, CDNF (10 $\mu \mathrm{g})$, or glial cell line-derived neurotrophic factor (GDNF; $10 \mu \mathrm{g}$ ). (F) Two weeks later animals were given d-amphetamine $(2.5 \mathrm{mg} / \mathrm{kg}, \mathrm{SC})$ and locomotor activity was measured for $2 \mathrm{~h}$. Activity is shown as related to the control group. (G) Number of TH-positive cells in substantia nigra pars compacta shown in relation to the contralateral untreated side. $(\mathrm{H}) \mathrm{TH}$ optical density in substantia nigra pars reticulata shown as normalized to the control group. 


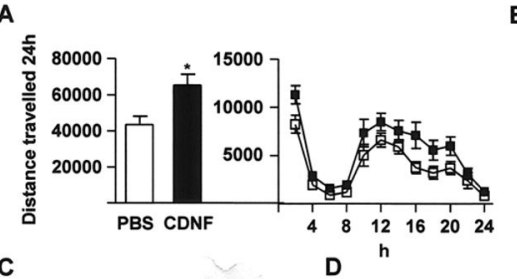

C

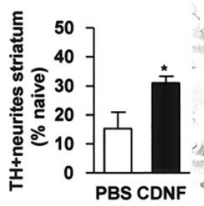

B

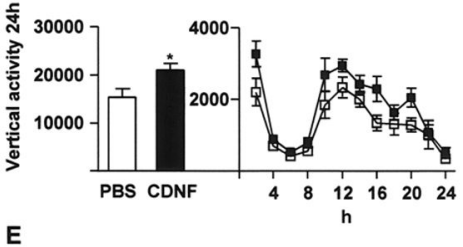

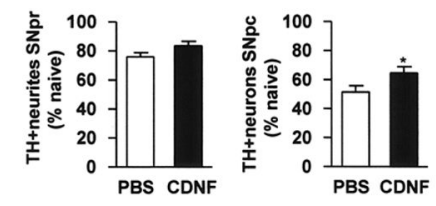

Figure 4. Striatal CDNF injections restore midbrain dopamine circuitry in the MPTP toxicity model

In the neurorestoration experiment, mice were balanced into two groups (PBS and CDNF 10 $\mu \mathrm{g}$ ) according to their 24-h behavior 1 week after MPTP injections. Bilateral PBS and CDNF injections were given into striatum and locomotor behavior and $\mathrm{TH}$ immunoreactivity were measured 1 week later. (A) Distance traveled. (B) Vertical activity. (C) TH optical density in the striatum. (D) TH optical density in the SNpr. (E) TH-positive cells in the SNpc. (A, B, E) $n=13-16,(\mathrm{C}, \mathrm{D}) n=4$. White bars and symbols represent PBS and black bars and symbols CDNF. The upper photomicrograph in $(\mathrm{C})$ is from the striatum of a CDNF-treated mouse and lower photomicrograph from a PBS-treated mouse. 


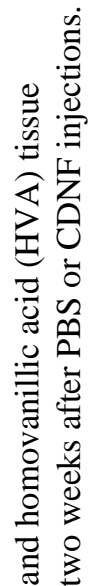

ชิ

官

을

氖

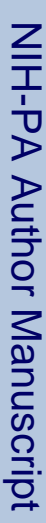

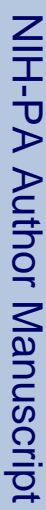

.

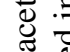

๘ 离

क्र

\begin{tabular}{|c|c|c|c|c|c|c|}
\hline \multicolumn{2}{|l|}{ 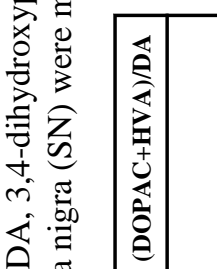 } & \multicolumn{3}{|c|}{ 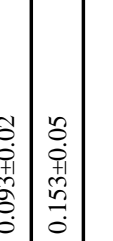 } & 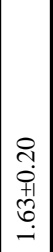 & \\
\hline \multirow{2}{*}{ 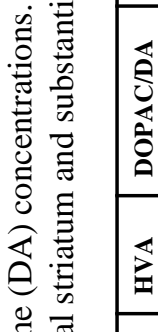 } & & $\begin{array}{l}0 \\
0 \\
01 \\
0 \\
0 \\
0\end{array}$ & 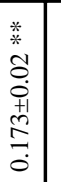 & & $\begin{array}{l}0 \\
0 \\
0 \\
01 \\
0 \\
0 \\
0 \\
0\end{array}$ & \\
\hline & & 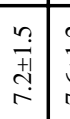 & | & & $\begin{array}{l}0 \\
0 \\
\dot{+} \\
+1 \\
0 \\
n \\
n\end{array}$ & $\begin{array}{l}t \\
0 \\
i n\end{array}$ \\
\hline \multirow{3}{*}{ 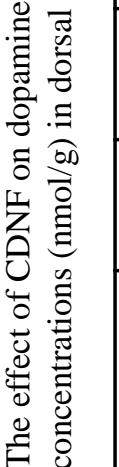 } & & \begin{tabular}{l|l}
7 \\
$\overrightarrow{+}$ \\
+1 \\
$\infty$ \\
$\infty$ \\
$\infty$
\end{tabular} & 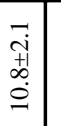 & & $\begin{array}{l}+ \\
\dot{0} \\
+ \\
\dot{1} \\
\dot{i}\end{array}$ & \\
\hline & & $\begin{array}{ll}9 & \\
0 & \\
+1 \\
1 \\
0 \\
0\end{array}$ & $\begin{array}{l}2 \\
\stackrel{2}{1} \\
+1 \\
\dot{8}\end{array}$ & & $\begin{array}{l}n \\
0 \\
+1 \\
n \\
n \\
m\end{array}$ & \\
\hline & 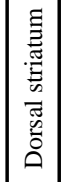 & $\stackrel{\tilde{\omega}}{\tilde{\omega}}$ & Uิ & \multicolumn{2}{|r|}{$\stackrel{\infty}{\infty}$} & \\
\hline
\end{tabular}

Cell Transplant. Author manuscript; available in PMC 2013 August 26. 